\title{
MODELING OF NATURAL CONVECTION OF A CONCENTRATED SOLAR POWER RECEIVER ABSORBER TUBE IN INTERACTION WITH NEIGHBOURING ABSORBERS
}

\author{
Olanrewaju Miracle Oyewola $\bowtie$ \\ School of Mechanical Engineering \\ Fiji National University \\ Suva, Fiji \\ Department of Mechanical Engineering ${ }^{l}$ \\ oooyewola001@gmail.com,olanrewaju.oyewola@fnu.ac.fj \\ Niyi Ezekiel Olukayode \\ Department of Mechanical Engineering \\ Ekiti State University \\ Ado-Ekiti, Nigeria, 362103 \\ Olusegun Olufemi Ajide \\ Department of Mechanical Engineering \\ University of Ibadan \\ Oduduwa Road, Ibadan, Nigeria, 200132 \\ ${ }^{1}$ University of Ibadan \\ Oduduwa Road, Ibadan, Nigeria, 200132
}

$\triangle$ Corresponding author

\begin{abstract}
Concentrated Solar Power (CSP) technology stands out among other renewable energy sources not only because of its ability to address current energy security and environmental challenges but because its energy can be stored for future use. To ensure optimum performance in this system, the heat losses need to be evaluated for better design.

This work studies the natural convection in the receiver absorber tube of a CSP plant taking into consideration the influence of neighboring absorbers. A 2-Dimensional model was adopted in this study. Initially, a single absorber tube was considered, it was subjected to heat flux at the top wall, the bottom wall was insulated and a temperature differential was set up at the lateral walls. The dimensionless forms of Navier-Stokes and energy equations were solved using the finite element formulation of COMSOL Multiphysics software. The result obtained for a single absorber tube showed good agreement with existing research works. This validated model was then extended to multiple absorber tubes (two to six absorber tubes). On the basis of the study, there is an observed increase in the intensity and dominance of convective heat transfer with an increase in the number of absorber tubes. This is occasioned by an increase in the average surface temperature as well as average Nusselt number. For the Rayleigh number of $10^{4}, 10^{5}$ and $10^{6}$, the average Nusselt number increases with the number of absorber tubes by $13.87 \%, 6.26 \%$, and $1.55 \%$, respectively. This increment suggests effect of thermal interactions among the neighboring absorber tubes.

Keywords: Concentrated Solar Power, Receiver Absorber Tubes, Natural convection, Dimensionless Parameters.
\end{abstract}

DOI: $10.21303 / 2461-4262.2021 .001871$

\section{Introduction}

The current global energy security and environmental challenges have shifted the world's focus into replacing fossil fuels with renewable energy sources. The use of Concentrated Solar Power (CSP) stands out among other renewable energy sources not only because it is environmentally benign or cost-effective but also because its energy can be harnessed and saved for future use.

Nomenclature Symbols: $g$ - acceleration due to gravity, $\mathrm{m} / \mathrm{s}^{2} ; \theta$-Dimensionless Temperature; $N u(X)$ - Local Nusselt number; $\mu$ - Dynamic viscosity; $N u_{\text {avg }}$ - Average Nusselt number; $\beta$ - Coefficient of volumetric expansion; $P$ - pressure, $\mathrm{Pa} ; \rho$ - Density of the heat transfer fluid, $\mathrm{kg} / \mathrm{m}^{3}$; 
$\operatorname{Pr}$ - Prandtl number; $\alpha$ - Thermal diffusivity; $q^{\prime \prime}$ - heat flux, W/m²; $v$ - Kinematic viscosity; $R a$ - Rayleigh Number; $T$ - Dimensional temperature, K.

Subscripts: $T_{h}$ - Temperature of hot wall; $K_{\text {avg }}$ - average; $T_{c}$ - Temperature of cold wall; $h$ - hot; $U$ - velocity in the $x$-direction, $\mathrm{m} / \mathrm{s} ; c$ - cold; $v$-velocity in the $y$-direction, $\mathrm{m} / \mathrm{s}$ in input; $L$ - Length; $u^{*}$ - Dimensionless form of velocity in $x$ direction; $v^{*}$ - Dimensionless form of velocity in $y$ direction; $x^{*}$ - Dimensionlessform of horizontal coordinate; $y^{*}$ - Dimensionless form of vertical coordinate; $p^{*}$ - Dimensionless form of pressure.

Even though this technology is attractive due to its ability to harness unlimited solar energy, the prevention of heat losses remains a big challenge. Avoiding or minimising heat losses will make CSP plant efficient and cost-effective. Natural convective heat loss in a CSP plant contributes a significant percentage to the overall heat loss in the system [1]. Therefore, research works on convective heat losses in CSP plants are very crucial to improving their performance efficiency. Considerable experimental and numerical studies have been conducted to evaluate heat losses in cavities, tubes, and receivers of concentrated solar power systems. One of such works was carried out by [2]. The authors developed a 3-D numerical model to simulate natural convection heat losses in a cavity receiver with plate fins. The influence of the orientation of the cavity and the number of plate fins were investigated. They found that convective heat loss from the cavity receiver was greatly affected by the inclination of the cavity, and by the number of plate fins. In addition, the total heat loss was also found to be reduced by using plate fins. Further, [3] numerically investigated natural convection heat transfer by subjecting the cavity to differential heating at the inclined walls. The source of heat was placed at the bottom wall and the governing equations were solved with ANSYS Fluent, finite volume-based software. The fluid flow and heat transfer activities within the cavity were found to depend on Rayleigh number, the heater's size and position as well as the aspect ratio of the cavity. A similar research work was carried out [4] involving a closed air-filled cavity using finite volume approach to evaluate the velocity vector, stream function, and temperature gradient. The influence of Rayleigh number was analyzed at different angles of inclination and the local and average Nusselt numbers were used to describe the activities of convective heat transfer at the flow regimes. In another dimension, a tilted open cavity was investigated by [5]. Natural convection heat transfer was studied numerically using both the laminar and Boussinesq approximation model. The governing equations were solved with a combination of finite volume method, SIMPLEC algorithm, SMART scheme, and Central Differencing scheme. Results were obtained for Rayleigh number ranging from $10^{4}$ to $10^{7}$ at different inclination angles of the cavity. They found that an increased in the inclination angles lead to a change in the average Nusselt number change. In addition, instabilities in airflow and Nusselt number oscillation were also observed at low inclination angle and high Rayleigh number. Remarkably, another notable 3-Dimensionalnumerical study was done to investigate heat losses in a Linear Fresnel Reflector (LFR) by [6]. They compared both convective and radiative heat losses at different values of heat transfer coefficient and emissivity, respectively. Convective heat losses were found to be higher at lower absorber tube temperature $(350 \mathrm{~K})$ and higher value of heat transfer coefficient $(25 \mathrm{~W} / \mathrm{mK})$ compared to heat loss by radiation. It worth noting that [7] investigated the trapezoidal cavity of a LFR consisting of eight absorber tubes where natural convective and radioactive heat losses were analyzed using both experimental and CFD methods. Eight heating elements were provided for the absorber tubes. Although radiation heat loss was found to be dominant, losses by natural convection were described as significant. The CFD results were found to be consistent with the experimental values.

Moreover, significant research works have also been done on parabolic trough collectors. For instance, [8] employed both numerical modeling and experimental measurements to study a $250 \mathrm{~kW}$ solar thermal power plant in order to compare heat losses in vacuum, lost vacuum (air) and broken glass (bare) tube. It was reported that there was a significant reduction in the heat losses in the absorber tube with vacuum relative to others. Further, by considering three different heat transfer fluids in a parabolic trough collector, [9] used COMSOL Multiphysics software with the assumption of constant flow rate of fluid to study three-dimensional temperature distributions of an absorber tube. The heat flux was evaluated with Microsoft Excel and compared to values from Soltrace software. In their research work, three different fluids were used as the heat transfer fluids and the 
simulation was carried out using $k-\varepsilon$ model. It was reported that a higher temperature was observed at the outlet of the absorber tube when the flow rate was $0.5 \mathrm{~m} / \mathrm{s}$ and solar flux was $938 \mathrm{~W} / \mathrm{m}^{2}$.

Despite numerous works on the subject matter, it worth noting that most of the works discussed in the literature (which encompasses parabolic trough collector and linear Fresnel reflector) did not take into consideration the effect of neighbouring absorber tubes in their models which might influence the heat transfer phenomena in the system. Hence, the contribution of neighboring absorber tubes to convective heat transfer activities has not been ascertained. The presence of multiple absorber tubes in a receiver whether evacuated or non-evacuated is expected to have a significant impact on the overall fluid flow and heat transfer in the assembly. This research work therefore numerically investigates the effect of neighboring absorber tubes in its study of natural convective heat transfer.

\section{Materials and Method}

Fig. 1 depicts the geometry of the problem. The absorber tube is represented in 2-D by a rectangular cavity filled with an incompressible fluid, water, which serves as the Heat Transfer Fluid (HTF). The absorber tube is enclosed in an air-filled cavity. The dimension of the absorber tube and the aspect ratio of the enclosure is maintained constant throughout the simulation. To generate a buoyancy-driven flow and to initiate convection, the left vertical wall is kept at a relatively low temperature $\left(T_{c}\right)$ and the right vertical wall is maintained at a relatively high temperature $\left(T_{h}\right)$. The top wall of the tube is subjected to uniform heat flux while the bottom wall is insulated. The properties of the HTF are assumed to be constant except for the density variation, which is approximated by the Boussinesq model.

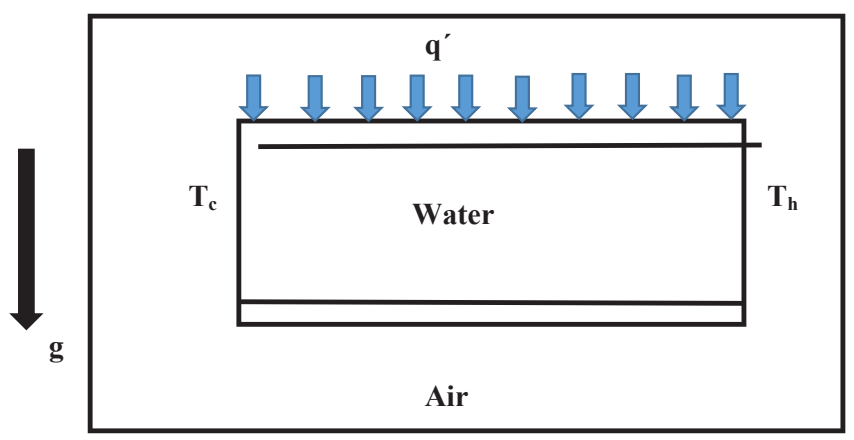

Fig. 1. Geometry of the 2D-Problem

The governing equations for the problem are described in two dimensions by the NavierStokes equation and the energy equation. The momentum equation in the $y$-direction has a buoyancy term, which is simplified using Boussinesq approximation.

The Dimensional Governing Equations were as follows:

Continuity Equation:

$$
\frac{\partial u}{\partial x}+\frac{\partial v}{\partial y}=0
$$

Momentum equation:

$$
\begin{gathered}
\rho\left(u \frac{\partial u}{\partial x}+v \frac{\partial u}{\partial y}\right)=-\frac{\partial p}{\partial x}+\mu\left(\frac{\partial^{2} u}{\partial x^{2}}+\frac{\partial^{2} u}{\partial y^{2}}\right) \\
\rho\left(u \frac{\partial v}{\partial x}+v \frac{\partial v}{\partial y}\right)=-\frac{\partial p}{\partial y}+\mu\left(\frac{\partial^{2} v}{\partial x^{2}}+\frac{\partial^{2} v}{\partial y^{2}}\right)+g \beta\left(T_{h}-T_{c}\right) .
\end{gathered}
$$

Energy equation:

$$
\rho\left(u \frac{\partial T}{\partial x}+v \frac{\partial T}{\partial y}\right)=\alpha\left(\frac{\partial^{2} T}{\partial x^{2}}+\frac{\partial^{2} T}{\partial y^{2}}\right) .
$$


The boundary conditions for the dimensional form of the governing equation are:

$$
\begin{aligned}
& x=0: u=v=0, T=T_{c}, \\
& x=L: u=v=0, T=T_{h}, \\
& y=h: \ddot{q}=q_{i n}, \\
& y=0: \ddot{q}=0 .
\end{aligned}
$$

Introducing Dimensionless Groups for the Governing Equations:

$$
\begin{aligned}
u^{*} & =\frac{L u}{\alpha} \tau^{*}=\frac{L v}{\alpha} x^{*}=\frac{x}{L}, \\
y^{*} & =\frac{y}{L}, \\
p^{*} & =\frac{p L^{2}}{\rho \alpha^{2}}, \\
\theta & =\frac{T-T_{c}}{T_{h}-T_{c}}, \\
\operatorname{Ra} & =\frac{\rho g \beta L^{3}\left(T_{h}-T_{c}\right)}{\mu \alpha}, \\
\operatorname{Pr} & =\frac{\mu}{\rho \alpha} .
\end{aligned}
$$

The dimensional equations are non-linear, the convective terms are therefore linearized and the non-dimensionless form of the governing equations is obtained:

$$
\begin{gathered}
\frac{\partial u}{\partial x}+\frac{\partial v}{\partial y}=0 \\
\left(u \frac{\partial u}{\partial x}+v \frac{\partial u}{\partial y}\right)=-\frac{\partial p}{\partial x}+\operatorname{Pr}\left(\frac{\partial^{2} u}{\partial x^{2}}+\frac{\partial^{2} u}{\partial y^{2}}\right) \\
\left(u \frac{\partial v}{\partial x}+v \frac{\partial v}{\partial y}\right)=-\frac{\partial p}{\partial y}+\operatorname{Pr}\left(\frac{\partial^{2} v}{\partial x^{2}}+\frac{\partial^{2} v}{\partial y^{2}}\right)+R a \operatorname{Pr} \theta \\
\rho\left(u \frac{\partial \theta}{\partial x}+v \frac{\partial \theta}{\partial y}\right)=\left(\frac{\partial^{2} \theta}{\partial x^{2}}+\frac{\partial^{2} \theta}{\partial y^{2}}\right)
\end{gathered}
$$

The boundary conditions for the dimensionless form of the governing equation are:

$$
\begin{aligned}
& x=0: u=v=0, \theta=0, \\
& x=L: u=v=0, \theta=1, \\
& y=h: \ddot{q}=1, \\
& y=0: \ddot{q}=0 .
\end{aligned}
$$

The dimensionless governing equations subjected to the aforementioned dimensionless boundary conditions were numerically solved using the finite element method based on Galerkin weighted residual formulation. The equation was modeled in COMSOL Multiphysics software. The computational domain of the absorber tube was meshed with triangular mesh elements using finer mesh size settings to capture the temperature and velocity changes near the walls. In heat transfer problems, it is customary to use the average Nusselt number as a measure of convective heat transfer rate in cavities. The Local Nusselt number was evaluated from the dimensionless temperature gradient and was integrated over the hot wall to obtain the average Nusselt number:

$$
N u(x)=\frac{\partial \theta}{\partial X}
$$




$$
N u_{\text {avg }}=\int_{0}^{1} N u(X) \mathrm{d} Y .
$$

The values of the average Nusselt number obtained for various Rayleigh numbers (Ra) were compared with previous research works to test the numerical model. The results were found to show reasonable agreements with related research works (Table 1).

Table 1

Comparison of present work with selected numerical studies

\begin{tabular}{ccccc}
\hline $\boldsymbol{R a}$ & $\mathbf{1 0}^{\mathbf{4}}$ & $\mathbf{1 0}^{\mathbf{5}}$ & $\mathbf{1 0}^{\mathbf{6}}$ \\
\hline Present Work & $\mathbf{2 . 2 8}$ & $\mathbf{4 . 5 4}$ & $\mathbf{8 . 5 0}$ \\
{$[10]$} & 2.240 & 4.51 & 8.82 \\
{$[11]$} & 2.246 & 4.521 & 8.984 \\
{$[12]$} & 2.302 & 4.646 & 9.012 \\
{$[13]$} & 2.247 & 4.532 & 8.893 \\
{$[14]$} & 2.234 & 4.517 & 8.948
\end{tabular}

The validated model was now extended to multiple tubes (two to six absorber tubes). The tubes were arranged to allow for uniform distribution of heat flux. The temperature distribution and average Nusselt numbers were compared for analysis.

\section{Results and Discussion}

In this study, natural convective heat transfer was investigated in an absorber tube enclosed in an air-filled cavity. The post-processed results obtained from the COMSOL Multiphysics interface are presented in Fig. 2 via isotherms and streamlines to provide a clear picture of changes occurring in the absorber tubes due toan increase in Rayleigh number. The average surface temperature and average Nusselt number were also evaluated from the COMSOL Multiphysics interface.

Fig. 2 shows the isotherms for Rayleigh numbers $R a=10^{4}, 10^{5}$ and $10^{6}$. It should be noted that Isotherms connect points of equal temperature in such that at every point along a given isotherm, the temperature values are the same.

At Rayleigh number of $10^{4}$, the near-uniform distribution of the isotherms close to the cold wall and the assumption of an almost parallel shape by the isotherms close to the hot wall indicate the predominance of conduction over convection. An explanation to this is the stagnancy of the fluid at that Rayleigh number. With increase in $R a$, fluid motion becomes significant and transition occurs from conduction to convection as indicated by the distortion of the isotherms. Apart from this, at higher values of Rayleigh number, the isotherm lines change sharply which is an indication of higher heat flux. This again implies that convection plays a dominant role in transferring heat. This corroborates and consistent with the findings of $[15,16]$. This is not surprising, Fig. 3 which is the streamlines for $R a=10^{4}, 10^{5}$, and $10^{6}$ support this assertion. It should be noted that convective cells are revealed with the aid of velocity streamlines. A large convective cell is seen to occupy the whole cavity. The fluid flow follows the boundaries and it is faster at the right vertical wall where there is highest variation of temperature.
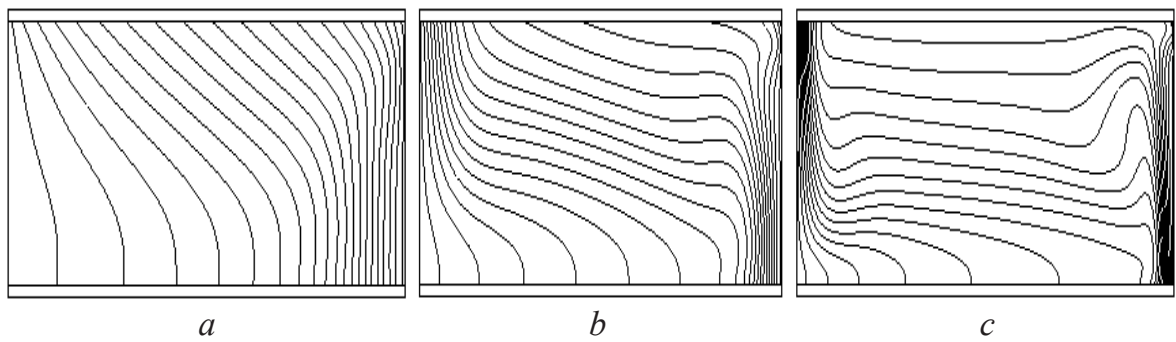

Fig. 2. Isotherms for $R a$ of: $a=10^{4} ; b=10^{5} ; c=10^{6}$ 

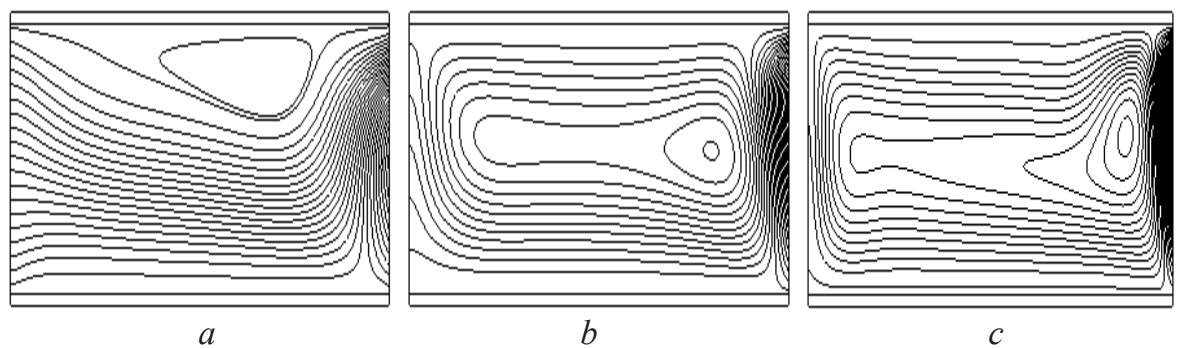

Fig. 3. Distribution of streamline for $R a$ of: $a=10^{4} ; b=10^{5} ; c=10^{6}$

The non-uniform distribution of streamline suggests flow flux is stronger at the outer region than in the core. At low Rayleigh number, there is less mixing of fluid due to less convection. The formation of a very weak eddy close to the top wall indicates low heat transfer activity. Meanwhile, as the Rayleigh number increases, heat transfer to the cold wall of the enclosure also increases. The buoyancy-driven flow induces recirculation zone in the absorber tube. As seen in the streamline plot of the velocity field, the elongation of the recirculation zone leads to a change in the streamline structure which is evidence of the supremacy of natural convection. The increase in Ra increases the strength of the flow and there is greater exchange of fluid between the left and right parts of the enclosure due to increased convection current.

The number of absorber tube in the enclosure which previously consisted of a single tube is increased and the value of the average surface temperature is evaluated in order to evaluate the influence of neighboring absorber tubes on the parameter. Table 2 shows the values obtained for various numbers of absorber tubes and the variation with Rayleigh number is shown in Fig. 4.

Table 2

Variation of average surface temperature with number of tubes

\begin{tabular}{ccccccc}
\hline \multirow{2}{*}{$\begin{array}{c}\text { Rayleigh } \\
\text { Number }\end{array}$} & \multicolumn{5}{c}{ Dimensionless temperature at different number of absorber tubes } \\
\cline { 2 - 7 } & One Tube & Two Tubes & Three Tubes & Four Tubes & Five Tubes & Six Tubes \\
\hline $10^{4}$ & 0.315 & 0.317 & 0.318 & 0.319 & 0.319 & 0.319 \\
$10^{5}$ & 0.426 & 0.427 & 0.429 & 0.429 & 0.429 & 0.429 \\
$10^{6}$ & 0.488 & 0.490 & 0.497 & 0.498 & 0.498 & 0.498
\end{tabular}

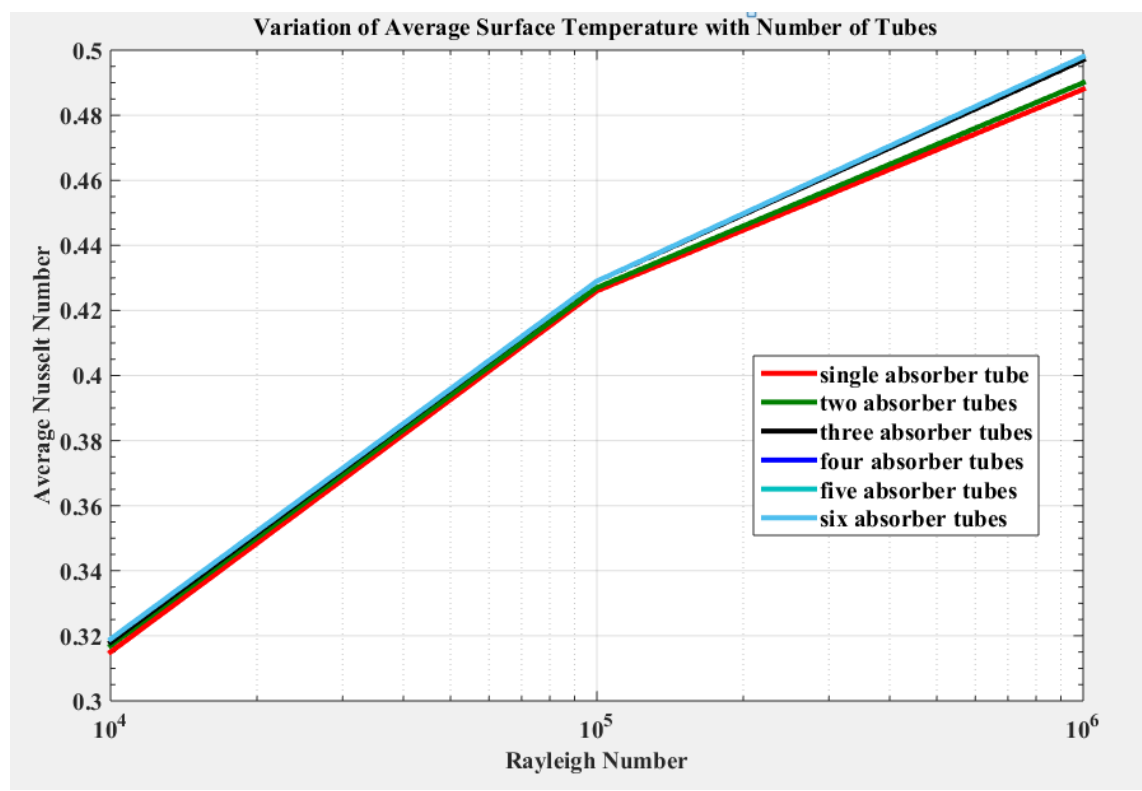

Fig. 4. Variation of average surface temperature with the number of tubes at different Rayleigh numbers 
Heat transfer performances are measured in terms of temperature of the fluid in the cavity as well as average Nusselt number at the hot surface. Fig. 4 shows the variation of the average surface temperature of the fluid with the Rayleigh number as well as the number of absorber tubes. Interestingly, as the Rayleigh number increases, average surface temperature also increases. This is not surprising, since this higher temperature difference implies higher difference in density which is a driving force for natural convection. In a similar dimension, a significant increase is experienced when the number of absorber tubes is increased. Initially, increasing the number of absorber tubes brought about a significant increase in the average surface temperature. However, the temperature increase becomes insignificant with a further increase in the number of tubes (beyond three tubes). This is shown by the overlapping of the figures. This suggests that there is limitation to increment in the value of the average surface temperature of the fluid. In this present study the threshold is three tubes beyond this the effect is insignificant.

While the previous results showed that the number of absorber tubes play significant role on the heat transfer characteristics of the system, to investigate further the influence of absorber tubes on the rate of convective heat transfer, the variation of average Nusselt number with Rayleigh number and also with the number of absorber tubes were computed as shown in Table 3. Similarly, Fig. 5 depicts the variation of average Nusselt number with Rayleigh number for various number of absorber tubes. The Fig. 5 shows an increase in the average Nusselt number with the Rayleigh number which implies that the intensity of convective heat transfer grows with Rayleigh number. This conforms to the findings of $[4,6,15,17]$. Although the authors only considered single tube, the increase in the gradient of the lines at Rayleigh number of $10^{5}$ indicates enhancement of heat transfer due to convection over conduction at higher values of $R a$.

Table 3

Variation of Average Nusselt Number with Number of Tubes

\begin{tabular}{ccccccc}
\hline \multirow{2}{*}{$\begin{array}{c}\text { Rayleigh } \\
\text { Number }\end{array}$} & \multicolumn{6}{c}{$\mathbf{N u}_{\text {avg }}$ at different number of absorber tubes } \\
\cline { 2 - 7 } & One Tube & Two Tubes & Three Tubes & Four Tubes & Five Tubes & Six Tubes \\
\hline $\mathbf{1 0}^{\mathbf{4}}$ & $\mathbf{2 . 2 8}$ & $\mathbf{3 . 1 8}$ & $\mathbf{4 . 0 6}$ & $\mathbf{4 . 0 7}$ & $\mathbf{4 . 1 2}$ & $\mathbf{4 . 1 5}$ \\
$10^{5}$ & 4.54 & 5.18 & 5.74 & 5.75 & 5.77 & 6.11 \\
$10^{6}$ & 8.50 & 8.57 & 8.63 & 8.71 & 8.98 & 9.18
\end{tabular}

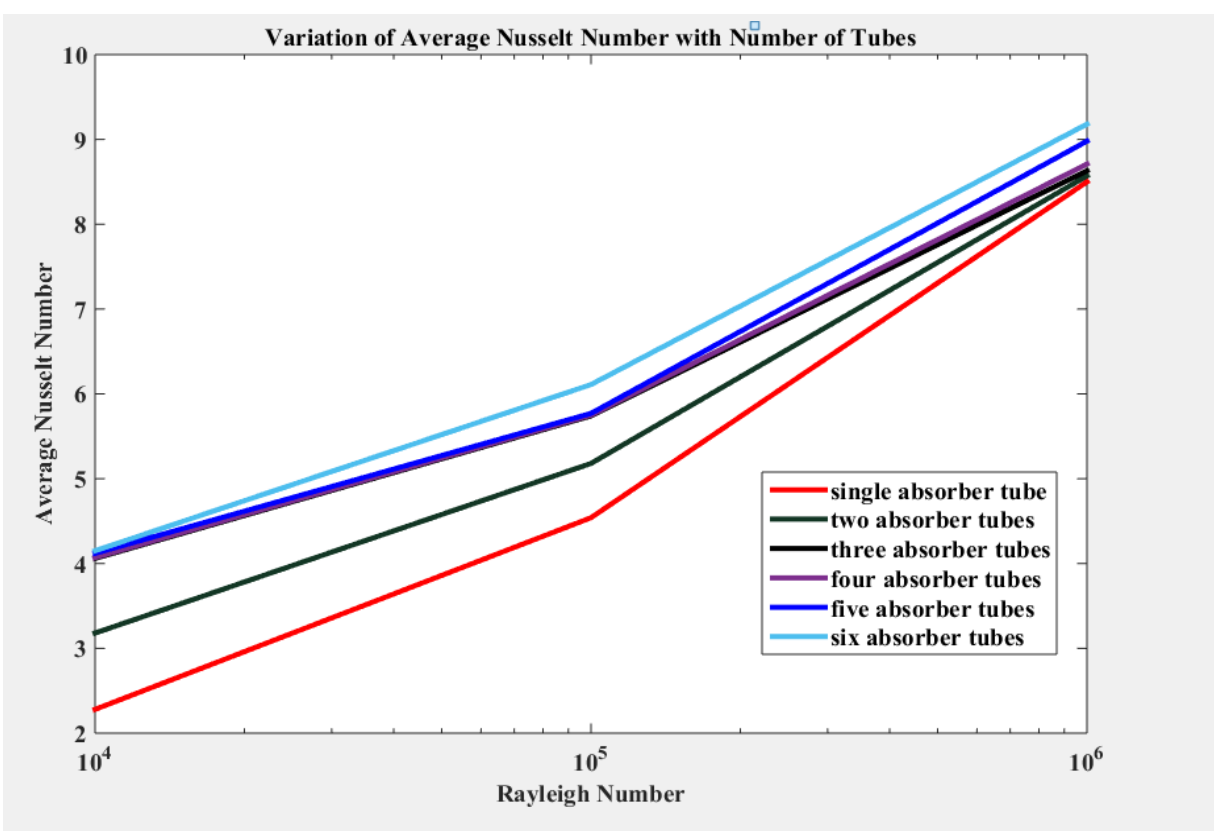

Fig. 5. Variation of average Nusseltnumber with number of tubes 
Similarly, as the number of absorber tubes increases, the average Nusselt number is also found to increase. For instance, for the Rayleigh number of $10^{4}, 10^{5}$ and $10^{6}$, the average Nusselt number increase with the number of absorber tubes by $13.87 \%, 6.26 \%$, and $1.55 \%$, respectively. This is not surprising, since natural convection depends on macroscopic movement of fluid particles. Therefore, it can be inferred that the thermal influence of the neighboring absorber tubes facilitates an increase in the flow of the heat transfer fluid in each absorber tubes, which leads to higher heat transfer by natural convection.

It should be noted that this study is limited in scope to natural convection, laminar, and steady flow. However, future studies should explore scenarios involving forced, or mixed convection and time-dependent turbulent flow. Experiments should also be used to validate the findings of the numerical modelling.

\section{Conclusions}

1. At low Rayleigh number $\left(10^{4}\right)$, conduction is the dominant heat transfer mechanism, the influence of convective heat transfer increased with Rayleigh number.

2. There was an increased in the average surface temperature of the absorber tube with Rayleigh number. The average Nusselt number was also found to increase with Rayleigh number indicated that intensity of convective heat transfer grows with Rayleigh number.

3. There was a significant increase in the average Nusselt number with an increase in the number of absorber tubes. For the Rayleigh number of $10^{4}, 10^{5}$ and $10^{6}$, the average Nusselt number increased with the number of absorber tubes by $13.87 \%, 6.26 \%$, and $1.55 \%$, respectively. This showed that there is increase in the intensity of convective heat transfer as the number of absorber tubes increases. This increment can be attributed to thermal interactions among the neighboring absorber tubes.

\section{References}

[1] Taumoefolau, T., Paitoonsurikarn, S., Hughes, G., Lovegrove, K. (2004). Experimental Investigation of Natural Convection Heat Loss From a Model Solar Concentrator Cavity Receiver. Journal of Solar Energy Engineering, 126 (2), $801-807$. doi: https://doi.org/10.1115/1.1687403

[2] Ngo, L. C., Bello-Ochende, T., Meyer, J. P. (2014). Numerical Modelling of Combined Natural Convection and Surface Radiation Heat Transfer in Cavity Receiver with Plate Fins. Proceedings of the 15th International Heat Transfer Conference. doi: https://doi.org/10.1615/ihtc15.rne.009869

[3] Sojoudi, A., Saha, S. C., Gu, Y. T. (2015). Natural convection due to differential heating of inclined walls and heat source placed on bottom wall of an attic shaped space. Energy and Buildings, 89, 153-162. doi: https://doi.org/10.1016/j.enbuild.2014.12.042

[4] Kristian, L., Bernard, F. (2002). Free convection heat losses in a flat plate solar collector. Energy and the Environment, $101-114$.

[5] Hinojosa, J. F., Alvarez, G., Estrada, C. A. (2006). Three-dimensional numerical simulation of the natural convection in an open tilted cubic cavity. Revista Mexicana De Fi'Sica, 52 (2), 111-119.

[6] Duggal, R., Jilte, R. (2017). Numerical Investigation on Trapezoidal Cavity Receiver Used In LFR with Water Flow in Absorber Tubes. IOP Conference Series: Materials Science and Engineering, 187, 012026. doi: https://oi.org/10.1088/ $1757-899 x / 187 / 1 / 012026$

[7] Sudhansu, S. S., Vargheseb, S. M., Kumarb, A., Kumarb, S. Singha, S., Banerjeea, R. (2011). An experimental and computational investigation of heat losses from the cavity receiver used in Linear Fresnel Reflector solar thermal system. Proceedings of International Conference on Advances in Energy Research (ICAER).

[8] Yaghoubi, M., Ahmadi, F., Bandehee, M. (2013). Analysis of Heat Losses of Absorber Tubes of Parabolic through Collector of Shiraz (Iran) Solar Power Plant. Journal of Clean Energy Technologies, 1 (1), 33-37. doi: https://doi.org/10.7763/jocet.2013.v1.8

[9] Mon, M. M., Soe, M. M., Htay, M. M. (2015). 3D modeling of temperature distribution for absorber tube of parabolic trough collector. International Journal of Engineering and Applied Sciences (IJEAS), 2 (6), 99-103.

[10] Nag, A., Sarkar, A., Sastri, V. M. K. (1993). Natural convection in a differentially heated square cavity with a horizontal partition plate on the hot wall. Computer Methods in Applied Mechanics and Engineering, 110 (1-2), $143-156$. doi: https://doi.org/10.1016/0045-7825(93)90025-s

[11] Ghafouri, A., Jozaei, A. F., Salari, M. (2015). Numerical evaluation of Nusselt number on the hot wall in square enclosure filled with nanofluid. International Journal of Mechanical, Aerospace, Industrial, Mechatronic and Manufacturing Engineering, 9 (2), 360-364. 
[12] Fusegi, T., Hyun, J. M., Kuwahara, K., Farouk, B. (1991). A numerical study of three-dimensional natural convection in a differentially heated cubical enclosure. International Journal of Heat and Mass Transfer, 34 (6), $1543-1557$. doi: https://doi.org/10.1016/0017-9310(91)90295-p

[13] Shi, X., Khodadadi, J. M. (2003). Laminar Natural Convection Heat Transfer in a Differentially Heated Square Cavity Due to a Thin Fin on the Hot Wall. Journal of Heat Transfer, 125 (4), 624-634. doi: https://doi.org/10.1115/1.1571847

[14] Elatar, A., Teamah, M. A., Hassab, M. A. (2016). Numerical study of laminar natural convection inside square enclosure with single horizontal fin. International Journal of Thermal Sciences, 99, 41-51. doi: https://doi.org/10.1016/ j.ijthermalsci.2015.08.003

[15] Omar, M. A., Ghalib, Y. K. (2015). Numerical Investigation of Natural Convection Heat Transferfrom Square Cylinder in an Enclosed Enclosure Filled with Nanofluids. International Journal of Recent Advances in Mechanical Engineering, 4 (4), 1-17. doi: https://doi.org/10.14810/ijmech.2015.4401

[16] Yao, S.-G., Duan, L.-B., Ma, Z.-S., Jia, X.-W. (2014). The Study of Natural Convection Heat Transfer in a Partially Porous Cavity Based on LBM. The Open Fuels and Energy Science Journal, 7 (1), 88-93. doi: https://doi.org/10.2174/1876973x01407010088

[17] Moukalled, F., Acharya, S. (2000). Natural convection in trapezoidal cavities with baffles mounted on the upper inclined surfaces. Numerical Heat Transfer, Part A: Applications, 37 (6), 545-565. doi: https://doi.org/10.1080/104077800274082

How to cite: Oyewola, O. M., Olukayode, N. E., Ajide, O. O. (2021). Modeling of natural convection of a concentrated solar power receiver absorber tube in interaction with neighbouring absorbers. EUREKA: Physics and Engineering, 5, 53-61. doi: https://doi.org/10.21303/2461-4262.2021.001871 